Original Article

\title{
Effectiveness of Exercises on Low Back Pain among Middle Aged Women at Puducherry
}

\author{
P. Sumathy \\ Professor, Kasturba Gandhi Nursing College, Sri Balaji Vidyapeeth, Puducherry - 607403. \\ Correspondence \\ P. Sumathy \\ Professor, Kasturba Gandhi Nursing College, Sri Balaji Vidyapeeth, \\ Mahatma Gandhi M edical College and Research Institute Campus, Pillaiyarkuppam, Puducherry - 607 403, India. \\ Mobile : +91 9944759280 E-mail : sumirhythm2005@yahoo.com
}

\begin{abstract}
Background: Women in their 30's, 40's and 50's have a higher incidence of low back pain due to a combination of risk factors that typically appears in the middle age. Addressing these underlying causes can significantly reduce the incidence of back pain .The objectives of the study were to assess the level of low back pain among middle aged women and to determine the effectiveness of selected exercises on low back pain among middle aged women .
\end{abstract}

Materials and Methods : A quasi experimental research design was adopted. The data were collected using Demographic proforma and Mc Caffery pain scale. 40 subjects with low back pain were identified and exercises that consisted of abdominal strengthening, back strengthening and hip stretching exercises were taught and practiced by them daily for half an hour for a period of one month. Frequency, Percentage 't' tests \& chi-square were used for analysis.

Results: The results showed a significant difference in pretest and post test pain levels at $p \varangle 0.001$ level.

Conclusion : The findings of the study implied that LBP is a common problem among middle aged women and doing exercises regularly would help to alleviate the pain.

Keywords: Low back pain, exercises, middle aged women

\section{Introduction}

Low back pain (LBP) is an emerging heath problem globally, where the middle aged people (35-58) years are more prone for back pain. The prevalence of LBP among women is found to be around $50 \%$ which is quite higher when compared to males and is a growing major health concern. ${ }^{1}$ The point prevalence of low back pain in Asian countries is around $28.5 \%{ }^{2}$. The incidence of low back pain increases as age advances. Low back pain in the middle aged women is characterized by non specific low back pain, where the cause is most difficult to identify. This is attributed to a combination of many risk factors that

Access this article online Quick Response Code

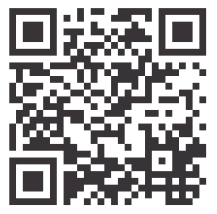
typically appears in the middle age. Women in this age group are highly active in their daily life, are exposed to various stresses, and are also more prone for LBP due to the nature of their occupation $^{3}$. By the time, middle age is reached, the bone strength, muscle elasticity and muscle tone starts to decline. The discs in the spine become drier and less flexible making them less able to cushion the vertebrae. This degeneration makes the spinal canal narrower leading to low back pain ${ }^{4}$

Moreover lack of exercises can worsen back pain due to increased stiffness, weakened muscles, and also due to the discs becoming malnourished and degenerated. M ost of it can be prevented, if few exercises are performed that helps to take the pressure off the back. The pain can be minimized by maintaining a healthy weight, correct body posture and practicing a healthy lifestyle $e^{5 .}$

Surveys related to people living with Low Back pain and its remedial measures are not carried out in the rural areas to a greater extent. Hence the researcher undertook the study in a rural area with the objective to assess the level of LBP among middle aged women, to determine the 
effectiveness of selected exercises on low back pain among middle aged women and to find out the association between the level of low back pain with selected demographic variables.

\section{Materialsand M ethods}

Quasi experimental study design was adopted where there was an Experimental and control group, but no randomization.

$\begin{array}{lccc}\text { Group } & \text { Pretest } & \text { Intervention } & \text { Post test } \\ \text { Experimental } & 01 & X & 02 \\ \text { Control } & 01 & - & 02\end{array}$

The study was conducted in Pillaiyarkuppam village of Puducherry .The population of the study included middle aged women between 35-58 years. A total of 40 samples were selected, where the first 20 identified with low back pain were assigned to experimental group and the remaining 20 to control group. Non probability purposive sampling technique was used to select the samples.

The instrument used to collect the data consisted of 2 parts.

Part I - consisted of the demographic data of women which included age, type of family, occupational status, educational status, number of siblings, duration of pain, BMl etc.,

Part II - Mc Caffery pain scale to assess the level of pain. It is a numerical scale where the user has the option to verbally rate the scale from $0-10$ or to place a mark on a line indicating their level of pain.
$0 \quad$ No Pain
0-3 Mild Pain
4-6 Moderate Pain
7-10 Severe Pain

After obtaining content validity from the experts the tool was used to collect data. The middle aged women who fulfilled the inclusion criteria were selected and consent was obtained from each participant. The level of low back pain was assessed for both experimental and control group. For subjects in the experimental group, exercises that consisted of abdominal muscle strengthening, back strengthening and hip stretching exercises were taught on the first day. The subjects continued to do the exercises for half an hour daily for 30 days under the supervision of the investigator. The post test was carried out on the $31^{\text {st }}$ day to assess the level of low back pain in both the experimental and control group.

\section{Statistical Methods}

Descriptive (frequency and percentage), and inferential statistics (paired $t$ test, independent $t$ test and chi square) were used for analysis of the study.

\section{Results}

1. Demographic socio-economic characteristics: Out of 40 samples majority of the women $19(47.5 \%)$ belonged to the age group of 40 - 45 years, 29(72.5\%) were homemakers, $16(40 \%)$ had a complaint of low back pain for 6 months-1year and $21(52.5 \%)$ were of normal weight and $12(30 \%)$ were overweight.

\section{Assessment of low back pain in the experimental and control group during pre test and post test.}

$12(60 \%)$ had moderate pain and $8(40 \%)$ had severe pain during pre test in the experimental group, whereas after the intervention $13(65 \%)$ had moderate pain, $7(35 \%)$ experienced mild pain and nobody experienced severe pain. In the control group 17 (85\%) had moderate pain and 3(15\%) experienced severe pain during pretest and in the post test there was no change in the level of pain.

Table : 1 Effectiveness of Exercises on Low Back Pain among women within the Experimental Group.

$\mathrm{N}=\mathbf{2 0}$

\begin{tabular}{|l|c|c|c|c|c|}
\hline Variable & Test & Mean & SD & t Value & P Value \\
\hline \multirow{2}{*}{ Low back pain } & Pre test & 5.75 & 1.12 & 5.9379 & $\mathrm{P}<0.001$ \\
\cline { 2 - 6 } & Post test & 3.80 & 0.95 & & \\
\hline
\end{tabular}

The mean pre test score was 5.75 and mean post test score was 3.80 with a SD of 1.12 and 0.95 respectively. The computed't' value was 5.9379 which was significant at $p<0.001$ level.

Table: 2 Effectiveness of Exercises on low back pain among women between the Experimental and Control group $\quad \mathbf{N}=\mathbf{4 0}$

\begin{tabular}{|l|c|c|c|c|c|}
\hline Variable & Group & M ean & SD & t Value & P Value \\
\hline \multirow{2}{*}{ Low back pain } & Experimental & 3.80 & 0.95 & 4.3397 & $\mathrm{P}<0.001$ \\
\cline { 2 - 6 } & Control & 5.30 & 1.22 & & \\
\hline
\end{tabular}


The mean value was 3.80 with a SD of 0.95 in the experimental group whereas the mean was found to be 5.30 with a SD of 1.22 in the control group. The computed t value was 4.3397 which was significant at $\mathrm{P}<0.001$ level.

1. There was no significant association between the level of low back pain with selected demographic variables.

\section{Discussion}

The prevalence of low back pain is a common problem among middle aged women. Out of 40 samples $29(72.5 \%)$ experienced moderate level of low back pain, and among that $19(47.5 \%)$ belonged to the age group of $40-45$ years, 29(72.5\%) were housewives and 17(42.5\%) experienced pain more often.

A study done at Rural Bangladesh revealed that the mean age of occurrence of low back pain was 45 years and 70\% were housewives. Female vulnerability is due to their occupation (housewife) which involved bending and twisting movements of the spine ${ }^{\cdot 6}$

In the present study majority of the women $\mathbf{1 2 ( 6 0 \% ) ~ h a d ~}$ moderate level of pain, $8(40 \%)$ had severe pain and none experienced mild pain. But after the exercises, nobody

\section{References}

1. Anil Chankaramangalam Mathew, Rowther Shamna Safar, Sathyam Anithadevi, M oosa Saira Banu. Prevalence and co-relates of low back pain in adults - A cross sectional study from South India. International Journal of M edicine and Public Health 2013; 3 (4): 342-346.

2. Tomita S. Arphorn S. Muto T. Prevalence and risk factors of low back pain among Thai and Myanmar migrant seafood processing factory workers in Samit Sahorn Province. Thailand Ind .Health 2014; 48: 28391.

3. www.backpain expert.co .uk.

4. Damian Hoy, Christopher Bain. A Systematic Review of Global Prevalence of Low Back Pain - Arthritis And Rheumatism. 2012; 64(6).

5. www.spine.health.com

6. Aminudin A Khan, Mohammed Moin Uddin,Ashanul Hoque Chowdhury, Ranjan Kumar Guha. Association of Low back pain with common risk factors-A Community based study. IJPM R 2014; 25(2).

7. Kumar T, Kumar S, Nezamuddin M, Sharma VP. Efficacy of core muscle Strenghthening Exercise in Chronic Low Back Pain Patients. Journal of Back and Rehabilitation 2014. experienced severe pain, 7 (35\%) had mild pain and 13 (65\%), experienced moderate level of pain.

Moreover the effectiveness of exercises within the experimental and between the control group was found to be highly significant at $\mathrm{P} \varangle 0.001$ level.

The findings were supported by a study conducted in $\mathbf{2 0 1 4}$ on the efficacy of muscle strengthening exercises among patients with chronic low back pain. The results revealed that after the muscle strengthening exercises the level of pain as measured by the numeric rating scale was reduced after the intervention, and there was no significant improvement in the level of pain in the control group ${ }^{7}$.

\section{Conclusion}

M ost of the women experience low back pain in their daily lives. Lack of exercises can aggravate this condition. Exercises offer a real potential for improving the health status and quality of life. Hence every woman should spare time to do exercises on a regular basis which goes a long way in their lives that is cost effective and prevents complications. 